\title{
The Impact of Health Systems on Diabetes Care in Low and Lower Middle Income Countries
}

\author{
David Beran
}

Published online: 28 February 2015

(C) Springer Science+Business Media New York 2015

\begin{abstract}
This review will highlight the current challenges and barriers to diabetes management in low and lower middle income countries using the World Health Organization's 6 Building Blocks for Health Systems (service delivery; healthcare workforce; information; medical products, vaccines and technologies; financing; and leadership and governance). Low and lower middle income countries are characterized by low levels of income and insufficient health expenditure. These countries face a shift in disease burden from communicable to noncommunicable diseases including diabetes. Many argue that health systems in these countries do not have the capacity to meet the needs of people with chronic conditions such as diabetes. A variety of barriers exist in terms of organization of health systems and care, human resources, sufficient information for decision-making, availability and affordability of medicines, policies, and alleviating the financial burden of care. These health system barriers need to be addressed, taking into account the need to have diabetes included in the global development agenda and also tailoring the response to local contexts including the needs of people with diabetes.
\end{abstract}

Keywords Diabetes $\cdot$ Health systems $\cdot$ Low income populations

\section{Introduction}

Low income countries (LIC) and lower middle income countries (LMIC) are facing an epidemiological transition, with

This article is part of the Topical Collection on Health Care Delivery Systems and Implementation in Diabetes

D. Beran $(\bowtie)$

Division of Tropical and Humanitarian Medicine, Geneva University

Hospitals and University of Geneva, Rue Gabrielle-Perret-Gentil 6,

CH-1211 Geneva 14, Switzerland

e-mail: david.beran@unige.ch increases in the prevalence and mortality related to noncommunicable diseases such as diabetes. These transitional patterns have close links to globalization, urbanization, and changes in the economic, social, and demographic profiles of these countries $[1,2]$. Often thought of as a disease of the rich, diabetes is now impacting all social classes in LICs and LMICs [3]. Health systems play a key role in the control and management of diabetes [4]. The management of diabetes poses a problem as health systems are not organized for long-term care of individuals, but rather acute care [5]. The management of diabetes requires regular availability of drugs, laboratory facilities, data collection tools, a trained healthcare team, and educated and empowered patients in addition to health services tailored to the social and cultural characteristics of patients [5, 6]. In addition to impacting health, diabetes also impacts social and economic aspects for the individual [7-9]. This review will focus on the current challenges and barriers to diabetes management in LICs and LMICs using the World Health Organization's 6 Building Blocks for Health Systems, namely service delivery; healthcare workforce; information; medical products, vaccines and technologies; financing; and leadership and governance, highlighting current challenges and possible opportunities for LICs and LMICs to tackle these.

\section{What is a Low Income or Lower Middle Income Country?}

The World Bank distinguishes countries by gross national income per capita in four categories: LIC (US\$1045 or less), LMIC (US\$ 1046 to US\$ 4125), upper middle income (US\$4126 to US\$12,745), and high income (HIC) (US\$12,746 or more) [10]. The focus of this paper will be on LICs and LMICs where $59.1 \%$ of the population live on less than US\$2.00 per day [11]. Besides low income per capita and high rates of poverty, these countries are also characterized 
by low expenditure on health. Average spending per person is US\$30 in LICs and US\$82 in LMICs in comparison to US\$4586 in HICs [12]. Ninety-four countries are included in the LIC and LMIC categories with $43 \%$ of these countries located in sub-Saharan Africa [10] (Appendix 1). This grouping of countries includes a very diverse mix of settings from India, Nigeria, Egypt as well as small Pacific Islands.

\section{The Burden of Diabetes}

Diabetes is one of the four conditions prioritized in the WHO's non-communicable disease agenda. Noncommunicable diseases are the main cause of mortality worldwide with $63 \%$ of total deaths [13]. Noncommunicable diseases have not replaced communicable diseases in LICs and LMICs, and therefore, these countries are facing a double burden of disease [14, 15, $16 \bullet \cdot$. The International Diabetes Federation (IDF) predicts that the number of people with diabetes will increase by $55 \%$ from 382 million in 2013 to 592 million by 2035 [17]. The increase in the prevalence of type 2 diabetes in LICs and LMICs between 2013 and 2035 will be $80 \%$ [17]. LICs and LMICs represent $35 \%$ of total cases and $46 \%$ of diabetes-related deaths (Appendix 1). One of the challenges with type 2 diabetes in these countries is the number of undiagnosed cases. For example, in Nicaragua, for every person diagnosed, over eight remain undiagnosed, and in Mozambique, in a population-based survey screening for diabetes, of those found to have diabetes when screened, only $13.3 \%$ were aware of their condition $[18,19,20 \bullet \bullet$.

In addition to the increasing burden of type 2 diabetes, LICs and LMICs need to manage people, especially children, with type 1 diabetes. It is estimated that 79 , 100 children under the age of 14 develop type 1 diabetes every year with a total of 497,100 children living with type 1 diabetes worldwide [17]. Data from 2009 shows that $40 \%$ of children aged $0-14$ with type 1 diabetes were from LIC and LMICs [21] (Appendix 1). LICs and LMICs face many social, economic, and health system factors that lead to poor diagnosis and treatment of type 1 diabetes. For example in Mozambique and Zambia, life expectancy for children with type 1 diabetes is 3.5 and 11.2 years at onset compared to normal life expectancy in HICs [22]. In a retrospective review of medical records over 10 years in the Democratic Republic of Congo, it was found that one out of six of people aged 30 years or below with type 1 diabetes had died, most within the first 5 years of diagnosis [23].

High rates of acute complications have also been found in people with diabetes in LICs and LMICs. Mortality rates for diabetic ketoacidosis (DKA) have been found to range from $10-30 \%$ in Nigeria and Ghana [24]. Diabetes was the fourth most common condition leading to critical illness after malaria, pneumonia, or influenza and respiratory diseases in the Solomon Islands [25].

Globally, diabetes treatment and its related complications cost US\$548 billion in 2013 [17]. Mean spending per person with diabetes in LICs and LMICs ranged from US\$20.9 to US\$545.2, with a median expenditure of US\$116.4 (Appendix 1). This compares to a range of US\$863 to US\$10,369 (median, US\$2356) in HICs.

For people with diabetes, health systems have as their aim the prevention of complications as well and other negative physical and psychosocial impacts of the disease [26, 27]. However, due to resource limitations and other barriers, health systems in LICs and LMICs are unable to provide the services that their populations need [28. and yet adapted to the delivery chronic care $[29,30 \bullet$.

\section{The Role of the Health System for Diabetes Care}

The United Nations (UN) in September 2011 held a summit on non-communicable diseases calling for a "whole of government and society approach [for the], prevention of risk factors, strengthening of policies and health systems, global collaboration and partnerships and research" [31]. This resulted in the World Health Organization (WHO) developing the Global Action Plan for the prevention and control of non-communicable diseases 2013-2020 with an overall target of a $25 \%$ relative reduction in premature mortality from noncommunicable diseases by 2025 [32]. The Global Action Plan aims to assist countries with their response to the challenge of non-communicable diseases and one of its objectives is to "strengthen and orient health systems to address the prevention and control of non-communicable diseases and the underlying social determinants through people-centered Primary Health Care and Universal Health Coverage" [32]. In order to achieve this, health systems will play an essential role.

In the World Health Report from the year 2000, the WHO states that a health system is an institution "whose primary purpose is to promote, restore and maintain health" [33]. Health systems do not work in isolation of the other sociopolitical elements of a given country and therefore different 
models of health systems exist $[34,35]$. However, each health system can be described based on the six key functions it must deliver [34]:

1. Service delivery

2. Healthcare workforce

3. Information

4. Medical products, vaccines, and technologies

5. Financing

6. Leadership and governance

\section{Service Delivery}

Service delivery is the what and how healthcare is delivered in a given context [34], and should be effective, safe, and centered on the patient's needs [36]. Care should be continuous and coordinated between different levels of the health system, diseases, and ages. It should also provide a comprehensive range of services from health promotion, prevention, curative, palliative, and rehabilitation. For diabetes, the comprehensive nature of care needs to include management of different elements of diabetes itself, e.g., specialist consultations for eye screenings or care, but also the joint management of diabetes and other conditions the person may have. Care should be accessible to the whole population without barriers (e.g., financial, language, culture, or geographical) and should be centered on the individual. People should also play an active role in their health and be educated and empowered to do so. For diabetes, improvements in service delivery are important as service dissatisfaction has been shown to be a cause of poor adherence to diabetes care [37•].

Typically, diabetes care in LICs and LMICs is delivered through diabetes clinics at different levels of the health system [38-41]. One example in Malawi highlights this with the diabetes clinic running twice per week, people arriving early in the morning to have their fasting blood glucose measured and then have their consultation carried out by a doctor or clinical officer in the afternoon [42]. Annual checks are carried out for nephropathy and retinopathy, but in many cases nothing can be done to treat these complications. However, these services in LICs and LMICs have been found to be predominantly provided in the capital city or large urban areas in hospitals [38-40]. Resources to treat diabetes at other levels of the health system (health centers, health posts, dispensaries) are lacking, leading to frequent referral to overburdened tertiary level facilities [43, 44]. People with diabetes also face poor coordination between medical staff, between inpatient and outpatient services, and between different hospitals and doctors. Because of the poor care received in many public facilities, some diabetes associations in LICs and LMICs actually provide direct diabetes care [39]. For example, in Mozambique, the main diabetes clinic in the capital city is run by the diabetes association in close association with the main hospital.

These system-level barriers are compounded by the socio-economic circumstances of the population. Studies suggest that rural, urban poor, marginalized, and indigenous and those with lower levels of education have less access to health services and may underutilize the services that are available [45-48]. In Mongolia, it was found that diabetes health-related knowledge was low in the whole population and that few had access to counseling or education services, but that the urban poor and least educated portions of the population faced additional barriers in their access to these services [48].

Geographic barriers to care may also result in a financial barrier. For example, with transportation to diabetes consultations representing the largest percentage of total cost for diabetes care in Vietnam [49] (Table 1). In LICs and LMICs, any cost is a barrier to service delivery, as people with diabetes spend a large portion of their income on their care as detailed in Table 1.

Clinical guidelines play an important role in the management of diabetes. The quality, use, and local applicability of guidelines in LICs and LMICs vary. The IDF has developed specific guidelines tailored to the African context [51]; however, in many contexts, guidelines either do not exist [38, 40, 43], may not be evidence based [52], or are established from international standards that may not be adapted to the local reality [19]. For example, in Indonesia, local guidelines have been developed and doctors are aware of these; however, uptake in daily practice was low [53]. The authors argue that this is due to lack of ownership, agreement, and adoption of guidelines.

In an assessment of barriers to care for diabetes in Kyrgyzstan, health professionals often stated that poor patient discipline was a problem in adhering to lifestyle recommendations [38]. However, from the patient perspective, poor adherence was linked to both a lack of education in conjunction to financial barriers. Patient education in different LICs and LMICs has been found to be variable [52, 54]. Different formats of educational sessions and materials are used in LICs and LMICs, such as peer educators, leaflets, healthcare worker-led education, etc. However, in some cases, issues exist about how adapted these are to the local context $[38,40]$. Doctors are often responsible for patient education, and it is usually delivered during the consultation. In some countries, diabetes associations also 
Table 1 Cost elements of diabetes care for individual patient with diabetes for six LICs and LMICs [38, 49, 50]

\begin{tabular}{|c|c|c|c|c|c|c|c|}
\hline \multirow[t]{2}{*}{ Country } & \multirow{2}{*}{$\begin{array}{l}\text { Total cost per } \\
\text { year (US\$) }\end{array}$} & \multicolumn{5}{|c|}{ Percentage of total cost } & \multirow{2}{*}{$\begin{array}{l}\text { Percentage of per } \\
\text { capita income }\end{array}$} \\
\hline & & Insulin & Syringes & Testing & Consultation & Travel & \\
\hline Kyrgyzstan (2009) & $\$ 80.4$ & 0 & 54 & 0 & 0 & 46 & 9 \\
\hline Mali (2004) & $\$ 339.4$ & 38 & 34 & 8 & 7 & 12 & 61 \\
\hline Mozambique (2003) & $\$ 273.6$ & 5 & 24 & 1 & 9 & 61 & 75 \\
\hline Mozambique (2009) & $\$ 359.8$ & 1 & 94 & 0 & 0 & 5 & 61 \\
\hline Nicaragua (2007) & $\$ 74.4$ & 0 & 73 & 0 & 0 & 27 & 7 \\
\hline Zambia (2003) & $\$ 199.1$ & 12 & 63 & 6 & 6 & 12 & 21 \\
\hline Vietnam (2008) & $\$ 427.0$ & 39 & 8 & 5 & 3 & 46 & 51 \\
\hline
\end{tabular}

Costs are $0 \%$ for services for which costs are covered by the government. Assumptions: Insulin, 1 vial per month; Syringes, 1 syringe per day; Testing, 1 blood glucose test per month; Consultation, 1 consultation per month; Travel, travel costs for 1 consultation per month

LIC low income countries, LMIC lower middle income countries

provide diabetes education $[39,52]$. Another route for patient education is the use of peers who can offer continuous support and firsthand knowledge of the day to day challenges of managing diabetes [55]. In Nicaragua, this exchange of experience between people with diabetes and their families is fostered by the diabetes association [19].

Traditional healers play an important role and are often the first port of call for people seeking healthcare [39]. These healers often use herbal plants for the treatment of diabetes [56-58]. A study in Egypt found that $42 \%$ of people with type 2 diabetes used complementary or alternative treatments [59]. The use of these treatments has been shown to have a negative impact on adherence to allopathic medicine $[37 \cdot, 59]$. A pilot project in Cameroon trained traditional healers in a range of aspects relating to diabetes, and this was found to have led to increased diabetes education by traditional healers and to increased referral by healers for blood glucose tests to health facilities [60].

Service delivery is the most complex issue to address as it is dependent on the other factors described below. Service delivery needs to focus on how prevention and health promotion activities are planned nationally, all the way down to how the individual consultation is organized. Prevention and promotion activities, appropriate guidelines, as well as the information and education that the person with diabetes receives need to be adapted to the local context and person. Use of community, peer educators, and traditional healers might be ways to achieve this tailored approach.

\section{Healthcare Workforce}

The health workforce includes not only the individuals within the health system whose role is to improve health [34], but also their knowledge, skills, and motivation in delivering health services.

In health systems assessments carried out in three sub-Saharan African countries, it was found that there were only two specialists and another 25-50 healthcare workers with some training in diabetes in the entire country [39]. For diabetes care, doctors often expressed that they were "scared" of managing diabetes. For example, in Zambia, only $9 \%$ of healthcare workers interviewed had received any form of special training in diabetes and only $33 \%$ felt sufficiently trained to treat a patient with diabetes [39]. A cross-sectional survey in Sri Lanka found gaps in knowledge and management of diabetes in general practitioners [61]. Doctors' training in diabetes mainly took place during their formal education with additional training being provided by diabetes associations, the pharmaceutical industry, or other organizations.

Doctors in LICs and LMICs are the only health cadre adequately trained to manage diabetes or prescribe diabetes medicines, but are not always involved in diabetes care or present at primary health care level [39, 43, 62]. In addition, many countries face a lack of additional human resources for diabetes, such as trained podiatrists [63] or nurses. Nurses and community health workers may be able to manage early or "mild" cases of diabetes, but currently such training is lacking. Approaches for task shifting in diabetes have been tried in Cameroon with nurses being used and have shown some promise [64, 65]. Some countries have also implemented training of trainers programs where training takes place at national, regional, and sub-regional levels $[50,66]$. In addition to these formal aspects of the health professionals' role, other elements such as relationships with patients, and 
addressing psychosocial problems are also seen as important and are currently lacking in LICs and LMICs [67].

It must be remembered that addressing diabetes in LICs and LMICs needs to take into account the severe shortage of health personnel in these countries. In LICs, there are only 2.4 doctors and 5.4 nurses per 10,000 population compared to 7.8 and 17.8 in LMICs and 29.4 and 86.9 in HICs, respectively [12]. Training for diabetes needs to be included in all parts of the medical curriculum at pre-graduate, post-graduate, and continuing medical education levels for both doctors and nurses. The issue of task shifting also needs to be addressed, but this may require certain laws to be changed, for example with regards to nurses prescribing rights.

\section{Information}

Information is an essential tool for the health system [34]. The information system needs to generate, compile, analyze, and synthesize data in order to help with decisions to improve the delivery of care and the way the health system operates. This can be at the level of an individual with a patient file, a facility-based register, sub-national or national statistics and surveillance systems as well as research and epidemiological studies. In many settings, a general lack of information at patient, facility, and national level exists [38-40]. Mendis et al. [62] in looking at gaps at primary health care for non-communicable diseases found that in eight countries (including seven LICs and LMICs) there were no computers and that $85 \% \mathrm{kept}$ paper-based patient files. In countries of the former Soviet Union, centralized data registries are present, but are seen as providing inaccurate data either due to errors in data entry or reports reflecting what is expected rather than reality $[43,52]$. This lack of easily accessible data has an impact on individual care, as well as for planning and management of supplies, medicines, and taking a system-wide approach to managing diabetes.

The WHO has stated that "research is fundamental to generate knowledge and information for formulating evidence-informed policies and practices in support of global public health and health equity" [68]. Data from research is needed to help improve all the six elements of the health system for diabetes management as well as a better understanding of the true burden of diabetes on health systems and individuals. While health systems collect a variety of information in LICs and LMICs, this information is not often used to make decisions either at the patient, facility, or system level. New information technologies may assist countries in collecting and disseminating this information, but a "culture" of data gathering, analysis, interpretation, and use needs to be instilled so that the information can help inform clinical decisions, ordering of medicines, and policies.

\section{Medical Products, Vaccines, and Technologies}

Health systems need to guarantee equitable access to medicines and other technologies, which are of assured quality, safety, efficacy, and cost-effectiveness and ensure that these are used in an evidence-based and cost-effective manner [34]. The WHO Essential Medicine List (EML) includes glibenclamide, gliclazide, insulin, and metformin for diabetes [69]. Various studies looking at the availability of diabetes medicines have found poor availability in the government sector in comparison to the private sector in LICs and LMICs [52, 70]. Overall availability of insulin in Mozambique and Zambia was found to be poor with only 20 and $42 \%$ of facilities having insulin present in two health system assessment surveys [49]. In a study of five LICs and LMICs, no country had $100 \%$ availability of at least one type of insulin (range 0-60\%; average $18 \%$ ) [71]. These problems can be linked to quantities ordered versus actually supplied as well as with distribution to peripheral areas $[22,52]$.

A variety of factors cause poor affordability of medicines in LICs and LMICs. These include irrational selection and purchase, mark-ups within the system and final patient price. For example, Kyrgyzstan purchased medicines not included on the WHO EML or its national EML. This meant that insufficient quantities of metformin (the most prescribed medicine) were purchased by the health system and therefore people requiring metformin had to purchase it in the private sector [52]. The out-of-pocket cost of metformin for people in Kyrgyzstan represented $7.4 \%$ of per capita GDP [38]. Kyrgyzstan also purchased analogue insulin, which is not included on the WHO EML, has significantly higher costs, and has been shown to have little added clinical value $[52,72]$.

Countries may also not utilize international reference prices (IRP), which give an idea of the "best" prices available for medicines on the international market. Cameron et al. [70] found that Ministries of Health in 36 developing and middle income countries were paying on average 2.2 times the IRP for glibenclamide. The same was true in Kyrgyzstan with the Ministry of Health purchasing glibenclamide and metformin at costs 5.4 and 10.3 times the IRP [52].

Different taxes and mark-ups further increase the price to the patient, meaning that for glibenclamide individuals from different WHO regions were paying anywhere from 3.2 to 211.9 times the IRP [70]. The price to the individual is also 
linked to availability, as if diabetes medicines are not available in the public sector individuals need to purchase these in the private sector where they are often more expensive. Another factor leading to higher prices is the use of branded rather than generic medicines.

The price of insulin to the Ministry of Health varied from US\$4.1 in Mozambique to US\$8.4 in Kyrgyzstan [49] (Fig. 1). Figure 1 shows that some countries had different prices between the government tender price and the price to the facility for transport and storage costs. In Vietnam, there is no centralized tendering with each facility conducting individual tenders. The average cost to the patient in the public sector was US\$1.13 per vial in Mozambique and US\$2.00 in Zambia, in comparison to US\$10.9 in Mali. Nicaragua and Kyrgyzstan provided insulin for free [49]. In the private sector, the price range was from US\$10.2 to US\$18.2, with this being out of reach for the majority of individuals in these countries [49]. In Malawi, Nepal, Pakistan and Sri Lanka the lowest paid government worker would need to spend 19.6, 7.3, 4.7 , and 6.1 days of wages, respectively, to afford 1 month of insulin [71].

Although four out of the six countries (Fig. 1) provide free or subsidized insulin, the annual cost of purchasing insulin for the health service in these countries would be US\$56.03, representing 40 times the annual public sector pharmaceutical expenditure per person [22]. The cold chain for insulin was not found to be a problem at facility level [39]. For individuals, innovative means of storage including clay pots have been described as means of addressing temperature control [73].

The public sector in Mali, Mozambique, and Zambia, at the time of the surveys, had very few syringes available for people and therefore these needed to be purchased in the private sector [39]. Patients in rural areas had the most difficulty accessing syringes. Some patients opted to reuse their syringes in part due to this cost (Table 1).

Availability and affordability was also an issue for diagnostic tools, with the necessary tools often lacking, particularly outside major urban centers [44, 49, 62]. For example, in 2003 , only $18 \%$ of health facilities in Mozambique had urine glucose strips, $8 \%$ ketone strips, and $21 \%$ a glucometer [22]. Affordability is also an issue when people need to pay for these tests (Table 1). In most LICs and LMICs, it is rare for individuals to have their own blood glucose meter.

To date, the response to problems of access to medicines for diabetes has focused on initiatives providing donations to certain countries run by the IDF, not for profits, or even the pharmaceutical industry [74-76]. A differential pricing

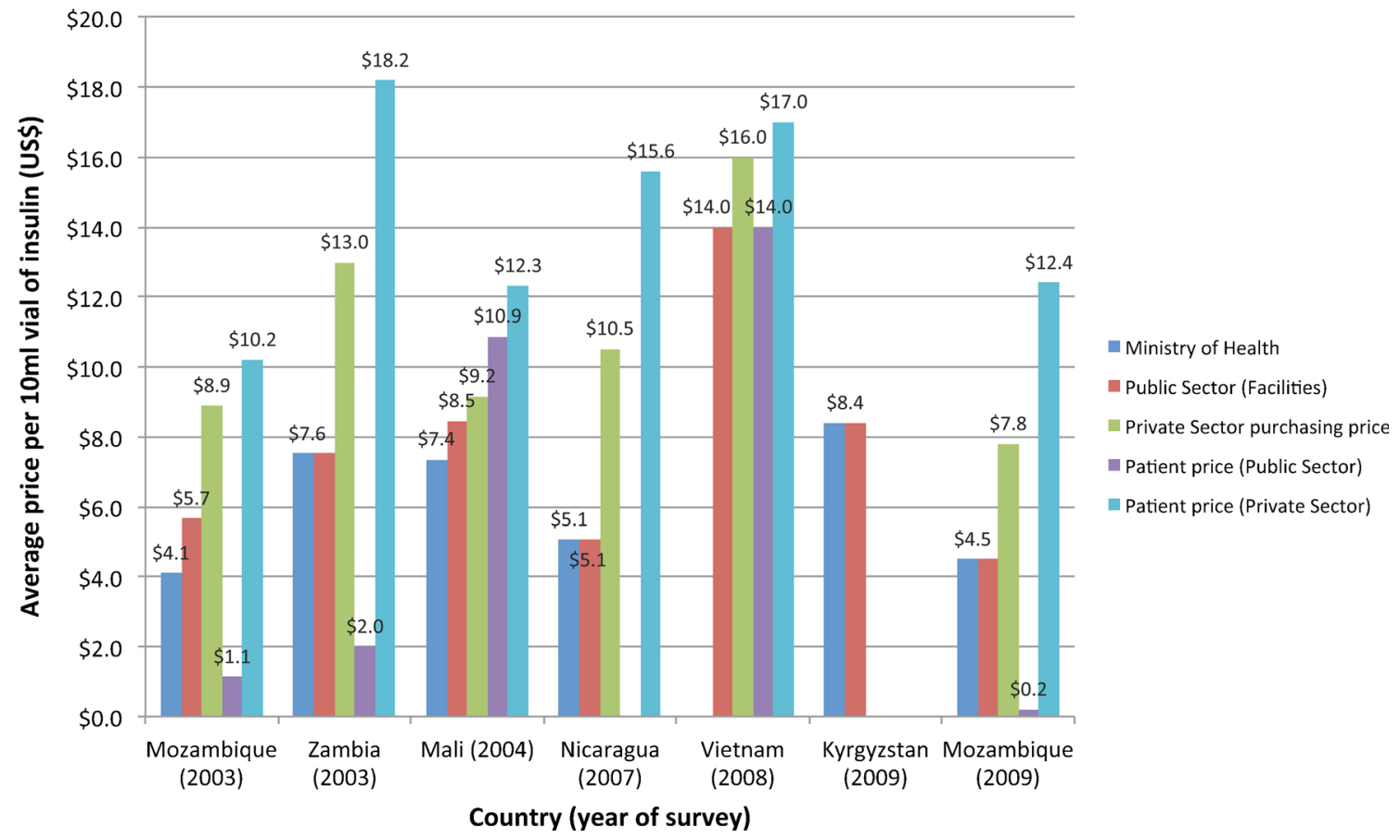

Fig. 1 Average prices of insulin (per $100 \mathrm{IU} 10 \mathrm{ml}$ vial) in six countries at different levels of the health system [49]. This figure shows the different prices of a vial of insulin at different levels of the health system. In Kyrgyzstan and Nicaragua, insulin is provided free to the individual in

the public sector, in comparison to Mali where one vial costs US\$10.90 in the public sector. The highest price in the public sector was US\$18.20 in Zambia 
mechanism for insulin has been established by one of the leading insulin manufacturers in 35 out of the 49 least developed countries [77], and this company has also established a pricing program in Kenya whereby the price of insulin has been set at 500 Kenyan shillings (approximately US\$5.7) for patients. The challenge with these initiatives is that they have not been evaluated and take a non-sustainable approach to addressing the root causes of poor access to medicines. The International Insulin Foundation, a UK-registered charity, has recently launched the 100 Campaign, which aims to reach $100 \%$ availability of insulin by the 100th anniversary of the first person receiving insulin in 2022 by raising awareness and finding creative means to address the barriers to access to insulin [78]. It has also been proposed that the WHO create a global clearing house for information on medicines in order for countries to be able to access the data they need to buy affordable, safe, effective, and quality-assured essential medicines [79].

\section{Leadership and Governance}

The governmental institution in LICs and LMICs responsible for addressing the challenge of diabetes is the Ministry of Health. As such, Ministries of Health play a critical leadership role in organizing and delivering care, as well as, involving other national stakeholders in health-related issues $[33,35]$. In a global survey of all countries, the WHO found that approximately $70 \%$ have a national strategy or plan to address the challenge of diabetes [13]. These plans should include prevention and health promotion, treatment and management as well as surveillance and monitoring and evaluation. Prevention activities in LICs and LMICs for diabetes varied greatly in their size and scope with the use of mass media, World Diabetes Day activities, and health education $[19,38,40]$.

As an example, the National Strategic Plan for the prevention and control of non-communicable diseases in Mozambique has as its aim to create a positive environment to minimize or eliminate the exposure to risk factors and guarantee access to care [80]. The plan which was approved by the Minister of Health in October 2008 aims to both guide local action as well as making a case why non-communicable diseases should be dealt with in Mozambique, thereby being useful as a tool for advocacy as well as a providing a framework for nationwide action.

In 2006, Kyrgyzstan passed a law to improve diabetes prevention and care although due to lack of resources not all of its elements have been implemented [38]. The law includes a focus on primary prevention and healthy lifestyles and emphasizes the need for social equity and fair access to prevention, treatment, and rehabilitation services. The law states that treatment for people with diabetes including insulin, oral medicines, and blood glucose monitoring should be available for free. Similar laws exist in Georgia and Ukraine, and mandate provision of insulin and emergency medical care for free [41, 43].

Non-communicable diseases have not been firmly placed on the development agenda or included in the Millennium Development Goals [81-83]. These goals started in the year 2000 and ending in 2015 have set the global agenda in terms of development and funding for health in LICs and LMICs. As LICs are highly dependent on donor aid with nearly $30 \%$ of funding for health coming from these sources [12], this lack of interest by donors for non-communicable diseases impacts the policy response countries develop. For example, the whole budget for the Ministry of Health in Mozambique for noncommunicable diseases was US\$97,000 in 2010 [80], limiting the response in a country with 22 million people.

Diabetes is not only an issue for the health system, and therefore, the leadership of the Ministry of Health has to go beyond the health sector in order to create a positive policy environment, which may include areas such as agriculture, urban planning, education, etc. This policy response needs to be shaped at the global, national, and local levels. This will require resources to focus on the wide issues that need to be addressed when looking at the prevention and care of diabetes.

\section{Financing}

In LICs and LMICs, a high proportion of money for healthcare comes from individuals in the form of out of pocket expenditure [28•]. The challenge in LICs and LMICs is to provide financial protection to the population with a very low formal sector and tax base. Globally, there is a push for LICs and LMICs to work towards Universal Health Coverage [84] and the non-communicable disease and Universal Health Coverage agendas from WHO's perspective are merging [85].

The financial burden that diabetes represents is considerable. For example, diabetes in Nicaragua already consumes $5 \%$ of the total health budget although only one in eight patients are cared for [19]. In combination with the barriers discussed in service delivery due to a lack of capacity both in terms of human resources and infrastructure and cost of care for people in LICs and LMICs, financing of diabetes care in LICs and LMICs is highly challenging. The WHO estimates that approximately $20 \%$ in LICs and $40 \%$ in LMICs of NCDrelated costs are covered by health insurance schemes in comparison to close to $90 \%$ in HICs [13].

To achieve Universal Health Coverage, countries need to address three key elements: who is covered; what services are 
covered; and how much of the cost is covered [84]. The other five health system elements detailed above show the challenges that exist for the successful implementation of all of these. In terms of coverage of the health system, this can be addressed by extending the services at primary health care. This however needs to take into account that in a country like Mozambique, only $40 \%$ of the population has access to health facilities [86]. Diabetes services will need to be extended by increasing training for diabetes care as well as the necessary infrastructure and medicines. In addressing the costs of care, decreasing the price of medicines as detailed above will assist with this. Some LICs and LMICs have addressed this by including diabetes medicines on National Health Insurance Schemes [54, 87].

\section{Conclusions and Future Directions}

Kyrgyzstan and Mozambique, two LICs, have shown some improvements in diabetes care following formal evaluations $[50,52]$. Lessons from these two countries show the importance of laws and policies, even if they are not fully implemented, which impact access to medicines, organization of care, human resources, and diagnostic tools. In both countries, there is an attempt to shift diabetes care to primary health care through the training of health personnel. Access to medicines has improved because of a mix of pressure by diabetes associations, results from past research, and the role that health professionals play in diabetes.

The challenge with delivering diabetes care in LICs and LMICs is that the prevalence is increasing, but not all those with diabetes are diagnosed, and health systems do not have the capacity to care for those already in the system with diabetes. In parallel, most systems do not yet integrate health promotion and prevention, therefore further increasing the burden on the system. This creates a vicious cycle of increasing numbers of people with diabetes and increased burden on the health system resulting in poor care. Compounding this challenge in people with diabetes in LICs and LMICs are comorbid conditions such as tuberculosis (TB) and therefore the challenge is not just diabetes, but the other health needs the individual may have [88].

Many authors have argued that models from HIV/AIDS and tuberculosis could be used for the management of diabetes in LICs and LMICs $[89,90]$. However, these responses were accompanied by substantial funding from global donors and took a vertical approach rather than a strengthening of the health system, and created silos of excellence for HIV/AIDS and TB $[91,92]$. There is therefore the need for health systems to take a comprehensive and integrative approach address the six elements of the health system by defining and organizing the roles of each level of the health system from primary health care to tertiary levels, with the focus on primary health care. The experience from HIV/AIDS shows that delivering medicines for a complex chronic condition is possible in LICs and LMICs [93••, 94], and countries need to follow existing best practice to ensure access to safe, effective, and qualityassured medicines at the best price possible as well as syringes and diagnostic tests. Information is vital for the proper management of the individual, procurement and planning process as well as prioritization and decision-making at the policy level. Prevention of diabetes is not only an issue for the health system, and therefore, the leadership of the Ministry of Health has to go beyond the health sector, for example by including government sectors responsible for education, agriculture, social protection, and urban planning.

Diabetes management even in HICs is problematic as health systems fail to address non-clinical aspects $[5,9,95$, 96]. This is due to problems within the health system as described above, but also the fact that diabetes is not managed within the health system, but predominantly at home, school, the workplace, and in the community [97•]. Zamzam et al. [67] in looking at barriers to control for diabetes in Syrian women found that work, family, social support, anxiety, depression, and low self-efficacy were barriers to proper diabetes management. This management of diabetes outside of the health system is all the more important in LICs and LMICs where the formal health system is underdeveloped.

The WHO's Global Action Plan provides countries with a roadmap for the global response to non-communicable diseases. However, diabetes and non-communicable diseases need to be included in the post-Millennium Development Goal agenda if the global community hopes to see similar results as the Millennium Development Goals. This global response needs to be accompanied by a national and local response that is adapted to the local circumstances of the country. The response to diabetes in Maputo, the capital of Mozambique is not the same as in Managua, the capital of Nicaragua or in Jeti-Oguz, a rural area in Kyrgyzstan. These local responses to diabetes need to be shaped from the policy level all the way to the needs of individuals in order to ensure that people with diabetes receive the care and support they need to effectively manage their condition.

\section{Compliance with Ethics Guidelines}

Conflict of Interest David Beran declares that he has no conflict of interest.

Human and Animal Rights and Informed Consent This article does not contain any studies with human or animal subjects performed by any of the authors. 


\section{Appendix}

Table 2 Data on the burden of diabetes in low income and lower middle income countries

\begin{tabular}{|c|c|c|c|c|c|c|c|c|}
\hline Country & $\begin{array}{l}\text { World } \\
\text { Bank } \\
\text { Income } \\
\text { Group [10] }\end{array}$ & $\begin{array}{l}\text { Total } \\
\text { population } \\
{[98]}\end{array}$ & $\begin{array}{l}\text { GDP per } \\
\text { capita (US\$) } \\
{[99]}\end{array}$ & $\begin{array}{l}\text { Diabetes } \\
\text { cases }\end{array}$ & $\begin{array}{l}\text { Diabetes } \\
\text { (type 2) } \\
\text { prevalence }\end{array}$ & $\begin{array}{l}\text { Diabetes- } \\
\text { related deaths } \\
\text { (cases) }\end{array}$ & $\begin{array}{l}\text { Mean diabetes- } \\
\text { related expenditure } \\
\text { per person with } \\
\text { diabetes (USD) }\end{array}$ & $\begin{array}{l}\text { Type } 1 \text { diabetes } \\
\text { cases }(0-14 \text { year: } \\
{[21]}\end{array}$ \\
\hline
\end{tabular}

[17]

\begin{tabular}{|c|c|c|c|c|c|c|c|c|}
\hline Afghanistan & LIC & $29,825,000$ & $\$ 678$ & 794,700 & $6.30(\%)$ & 18,864 & 102 & 1047 \\
\hline Armenia & LMIC & $2,969,000$ & $\$ 3505$ & 54,950 & $2.64(\%)$ & 979 & 187 & 268 \\
\hline Bangladesh & LIC & $155,000,000$ & $\$ 829$ & $5,089,040$ & $5.52(\%)$ & 102,139 & 41 & 14,256 \\
\hline Benin & LIC & $10,051,000$ & $\$ 805$ & 65,630 & $1.37(\%)$ & 1221 & 66 & 764 \\
\hline Bhutan & LMIC & 742,000 & $\$ 2498$ & 22,500 & $4.87(\%)$ & 124 & 143 & 7 \\
\hline $\begin{array}{l}\text { Bolivia (Plurinational } \\
\text { State of) }\end{array}$ & LMIC & $10,496,000$ & $\$ 2868$ & 361,090 & $6.29(\%)$ & 5260 & 185 & 111 \\
\hline Burkina Faso & LIC & $16,460,000$ & $\$ 684$ & 237,920 & $3.24(\%)$ & 6265 & 67 & 1312 \\
\hline Burundi & LIC & $9,850,000$ & $\$ 267$ & 178,260 & $3.91(\%)$ & 4829 & 41 & 236 \\
\hline Cambodia & LIC & $14,865,000$ & $\$ 1008$ & 221,430 & $2.54(\%)$ & 5540 & 81 & 95 \\
\hline Cameroon & LMIC & $21,700,000$ & $\$ 1315$ & 497,980 & $4.88(\%)$ & 13,822 & 116 & 1418 \\
\hline Cape Verde & LMIC & 494,000 & $\$ 3785$ & 15,850 & $5.48(\%)$ & 157 & 228 & 38 \\
\hline $\begin{array}{l}\text { Central African } \\
\text { Republic }\end{array}$ & LIC & $4,525,000$ & $\$ 333$ & 126,480 & $5.61(\%)$ & 3934 & 30 & 342 \\
\hline Chad & LIC & $12,448,000$ & $\$ 1046$ & 231,290 & $4.47(\%)$ & 6926 & 64 & 968 \\
\hline Comoros & LIC & 718,000 & $\$ 894$ & 23,740 & $6.76(\%)$ & 284 & 68 & 20 \\
\hline Côte d'Ivoire & LMIC & $19,840,000$ & $\$ 1521$ & 501,530 & $5.19(\%)$ & 11,884 & 133 & 1460 \\
\hline $\begin{array}{l}\text { Korea (Dem, People's } \\
\text { Republic) }\end{array}$ & LIC & $24,763,000$ & - & $1,251,660$ & $7.26(\%)$ & 31,329 & - & 348 \\
\hline $\begin{array}{l}\text { Congo (Dem, Republic } \\
\text { of the) }\end{array}$ & LIC & $65,705,000$ & $\$ 454$ & $1,594,110$ & $5.37(\%)$ & 33,280 & 34 & 1630 \\
\hline Djibouti & LMIC & 860,000 & $\$ 1668$ & 28,750 & $5.92(\%)$ & 533 & 161 & 195 \\
\hline Egypt & LMIC & $80,722,000$ & $\$ 3314$ & $7,510,600$ & $15.56(\%)$ & 86,478 & 176 & 12,622 \\
\hline El Salvador & LMIC & $6,297,000$ & $\$ 3826$ & 338,770 & $9.42(\%)$ & 3481 & 351 & 212 \\
\hline Eritrea & LIC & $6,131,000$ & $\$ 544$ & 130,930 & $4.43(\%)$ & 1720 & 24 & 43 \\
\hline Ethiopia & LIC & $91,729,000$ & $\$ 498$ & $1,852,230$ & $4.36(\%)$ & 34,262 & 29 & 518 \\
\hline Gambia & LIC & $1,791,000$ & $\$ 494$ & 12,400 & $1.55(\%)$ & 205 & 50 & 133 \\
\hline Georgia & LMIC & $4,358,000$ & $\$ 3602$ & 93,420 & $2.96(\%)$ & 1481 & 383 & 204 \\
\hline Ghana & LMIC & $25,366,000$ & $\$ 1850$ & 440,000 & $3.35(\%)$ & 8529 & 123 & 1652 \\
\hline Guatemala & LMIC & $15,083,000$ & $\$ 3478$ & 661,050 & $8.97(\%)$ & 7997 & 336 & 555 \\
\hline Guinea & LIC & $11,451,000$ & $\$ 527$ & 215,840 & $3.93(\%)$ & 3965 & 50 & 769 \\
\hline Guinea-Bissau & LIC & $1,664,000$ & $\$ 504$ & 27,240 & $3.35(\%)$ & 660 & 64 & 160 \\
\hline Guyana & LMIC & 795,000 & $\$ 3847$ & 60,150 & $14.08(\%)$ & 1098 & 292 & 1 \\
\hline Haiti & LIC & $10,174,000$ & $\$ 820$ & 309,510 & $5.58(\%)$ & 6302 & 92 & 112 \\
\hline Honduras & LMIC & $7,936,000$ & $\$ 2291$ & 268,810 & $6.28(\%)$ & 2625 & 198 & 259 \\
\hline India & LMIC & $1,240,000,000$ & $\$ 1499$ & $65,076,360$ & $8.56(\%)$ & $1,065,053$ & 84 & 97,600 \\
\hline Indonesia & LMIC & $247,000,000$ & $\$ 3475$ & $8,554,170$ & $5.55(\%)$ & 172,601 & 143 & 1188 \\
\hline Kenya & LIC & $43,178,000$ & $\$ 994$ & 749,250 & $3.58(\%)$ & 20,350 & 61 & 975 \\
\hline Kiribati & LMIC & 101,000 & $\$ 1651$ & 15,030 & $25.94(\%)$ & 152 & 211 & - \\
\hline Kyrgyzstan & LMIC & $5,474,000$ & $\$ 1263$ & 164,230 & $5.02(\%)$ & 2801 & 105 & 117 \\
\hline $\begin{array}{c}\text { Lao People's } \\
\text { Democratic } \\
\text { Republic }\end{array}$ & LMIC & $6,646,000$ & $\$ 1646$ & 157,880 & $4.44(\%)$ & 4133 & 62 & 41 \\
\hline Lesotho & LMIC & $2,052,000$ & $\$ 1075$ & 41,400 & $3.92(\%)$ & 2806 & 230 & 40 \\
\hline
\end{tabular}


Table 2 (continued)

\begin{tabular}{|c|c|c|c|c|c|c|c|c|}
\hline Country & $\begin{array}{l}\text { World } \\
\text { Bank } \\
\text { Income } \\
\text { Group [10] }\end{array}$ & $\begin{array}{l}\text { Total } \\
\text { population } \\
{[98]}\end{array}$ & $\begin{array}{l}\text { GDP per } \\
\text { capita (US\$) } \\
\text { [99] }\end{array}$ & $\begin{array}{l}\text { Diabetes } \\
\text { cases }\end{array}$ & $\begin{array}{l}\text { Diabetes } \\
\text { (type 2) } \\
\text { prevalence }\end{array}$ & $\begin{array}{l}\text { Diabetes- } \\
\text { related deaths } \\
\text { (cases) }\end{array}$ & $\begin{array}{l}\text { Mean diabetes- } \\
\text { related expenditure } \\
\text { per person with } \\
\text { diabetes (USD) }\end{array}$ & $\begin{array}{l}\text { Type } 1 \text { diabetes } \\
\text { cases }(0-14 \text { years }) \\
{[21]}\end{array}$ \\
\hline
\end{tabular}

[17]

\begin{tabular}{|c|c|c|c|c|c|c|c|c|}
\hline Liberia & LIC & $4,190,000$ & $\$ 454$ & 67,090 & $3.36(\%)$ & 1375 & 95 & 368 \\
\hline Madagascar & LIC & $22,294,000$ & $\$ 471$ & 352,210 & $3.33(\%)$ & 5298 & 33 & 783 \\
\hline Malawi & LIC & $15,906,000$ & $\$ 226$ & 372,350 & $5.26(\%)$ & 12,799 & 54 & 345 \\
\hline Mali & LIC & $14,854,000$ & $\$ 715$ & 81,980 & $1.28(\%)$ & 1972 & 84 & 1149 \\
\hline Mauritania & LMIC & $3,796,000$ & $\$ 1070$ & 87,610 & $4.57(\%)$ & 1288 & 96 & 235 \\
\hline Moldova (Republic of) & LMIC & $3,514,000$ & $\$ 2230$ & 72,090 & $2.77(\%)$ & 1320 & 287 & 220 \\
\hline Mongolia & LMIC & $2,796,000$ & $\$ 4056$ & 135,750 & $7.51(\%)$ & 3053 & 214 & 26 \\
\hline Morocco & LMIC & $32,521,000$ & $\$ 3109$ & $1,491,290$ & $7.29(\%)$ & 9426 & 260 & 4840 \\
\hline Mozambique & LIC & $25,203,000$ & $\$ 593$ & 278,380 & $2.46(\%)$ & 10,104 & 64 & 559 \\
\hline Myanmar & LIC & $52,797,000$ & - & $1,988,850$ & $5.70(\%)$ & 60,243 & 32 & 232 \\
\hline Nepal & LIC & $22,474,000$ & $\$ 694$ & 674,120 & $4.51(\%)$ & 14,531 & 39 & 404 \\
\hline Nicaragua & LMIC & $5,992,000$ & $\$ 1851$ & 344,310 & $10.25(\%)$ & 3308 & 155 & 187 \\
\hline Niger & LIC & $17,157,000$ & $\$ 413$ & 306,430 & $4.34(\%)$ & 5555 & 35 & 1360 \\
\hline Nigeria & LMIC & $169,000,000$ & $\$ 3006$ & $3,921,500$ & $4.99(\%)$ & 105,091 & 137 & 12,239 \\
\hline Pakistan & LMIC & $179,000,000$ & $\$ 1299$ & $6,712,700$ & $6.76(\%)$ & 87,354 & 46 & 1544 \\
\hline Papua New Guinea & LMIC & $7,167,000$ & $\$ 2088$ & 203,700 & $5.44(\%)$ & 5230 & 133 & 16 \\
\hline Paraguay & LMIC & $6,687,000$ & $\$ 4403$ & 236,810 & $6.17(\%)$ & 2243 & 545 & 119 \\
\hline Philippines & LMIC & $96,707,000$ & $\$ 2765$ & $3,256,210$ & $6.01(\%)$ & 54,535 & 154 & 7533 \\
\hline Congo (Republic of) & LMIC & $4,337,000$ & $\$ 3172$ & 114,570 & $5.48(\%)$ & 2549 & 146 & 82 \\
\hline Rwanda & LIC & $11,458,000$ & $\$ 633$ & 234,000 & $4.38(\%)$ & 5464 & 109 & 255 \\
\hline Samoa & LMIC & 189,000 & $\$ 3647$ & 6840 & $7.09(\%)$ & 161 & 400 & - \\
\hline Sao Tome and Principe & LMIC & 188,000 & $\$ 1610$ & 4790 & $5.19(\%)$ & 62 & 192 & 12 \\
\hline Senegal & LMIC & $13,726,000$ & $\$ 1072$ & 208,590 & $3.24(\%)$ & 3474 & 116 & 976 \\
\hline Sierra Leone & LIC & $5,979,000$ & $\$ 809$ & 96,150 & $3.30(\%)$ & 3094 & 118 & 479 \\
\hline Solomon Islands & LMIC & 550,000 & $\$ 1954$ & 35,510 & $12.96(\%)$ & 484 & 199 & 1 \\
\hline Somalia & LIC & $10,195,000$ & - & 244,050 & $5.59(\%)$ & 5234 & 21 & 78 \\
\hline South Sudan & LMIC & $10,838,000$ & $\$ 1221$ & 391,330 & $7.43(\%)$ & 7268 & - & - \\
\hline Sri Lanka & LMIC & $21,098,000$ & $\$ 3280$ & $1,128,010$ & $8.04(\%)$ & 16,276 & 127 & 1144 \\
\hline State of Palestine & LMIC & - & - & 134,620 & $6.55(\%)$ & - & - & 389 \\
\hline Sudan & LMIC & $37,195,000$ & $\$ 1753$ & $1,402,220$ & $7.74(\%)$ & 25,342 & 170 & 9996 \\
\hline Swaziland & LMIC & $1,231,000$ & $\$ 3034$ & 23,020 & $3.70(\%)$ & 1378 & 441 & 22 \\
\hline Syrian Arab Republic & LMIC & $21,890,000$ & - & 868,830 & $7.39(\%)$ & 8203 & 161 & 1466 \\
\hline Tajikistan & LIC & $8,009,000$ & $\$ 1037$ & 194,870 & $4.48(\%)$ & 2626 & 87 & 189 \\
\hline Timor-Leste & LMIC & $1,114,000$ & $\$ 1371$ & 26,710 & $5.85(\%)$ & 615 & 90 & 11 \\
\hline Togo & LIC & $6,643,000$ & $\$ 636$ & 130,150 & $4.02(\%)$ & 2516 & 74 & 536 \\
\hline Uganda & LIC & $36,346,000$ & $\$ 572$ & 625,050 & $4.14(\%)$ & 21,461 & 79 & 925 \\
\hline Ukraine & LMIC & $45,530,000$ & $\$ 3900$ & $1,043,580$ & $2.99(\%)$ & 20,654 & 314 & 3091 \\
\hline $\begin{array}{l}\text { Tanzania (United } \\
\text { Republic of) }\end{array}$ & LIC & $47,783,000$ & $\$ 695$ & $1,706,930$ & $7.80(\%)$ & 47,144 & 63 & 591 \\
\hline Uzbekistan & LMIC & $28,541,000$ & $\$ 1878$ & 880,510 & $5.05(\%)$ & 12,886 & 128 & 631 \\
\hline Vanuatu & LMIC & 247,000 & $\$ 3303$ & 27,950 & $21.04(\%)$ & 360 & 175 & 1 \\
\hline Vietnam & LMIC & $90,796,000$ & $\$ 1911$ & $3,299,110$ & $5.37(\%)$ & 54,953 & 128 & 445 \\
\hline Yemen & LMIC & $23,852,000$ & $\$ 1473$ & 708,120 & $6.12(\%)$ & 9892 & 151 & 1663 \\
\hline Zambia & LMIC & $14,075,000$ & $\$ 1540$ & 193,920 & $3.16(\%)$ & 7599 & 161 & 281 \\
\hline Zimbabwe & LIC & $13,724,000$ & $\$ 905$ & 600,670 & $8.83(\%)$ & 31,347 & 54 & 252 \\
\hline \multicolumn{4}{|l|}{ Total } & \multicolumn{2}{|l|}{$132,890,000$} & \multicolumn{2}{|l|}{$2,349,835$} & 197,391 \\
\hline
\end{tabular}


Table 2 (continued)

\begin{tabular}{|c|c|c|c|c|c|c|c|c|}
\hline Country & $\begin{array}{l}\text { World } \\
\text { Bank } \\
\text { Income } \\
\text { Group [10] }\end{array}$ & $\begin{array}{l}\text { Total } \\
\text { population } \\
{[98]}\end{array}$ & $\begin{array}{l}\text { GDP per } \\
\text { capita (US\$) } \\
\text { [99] }\end{array}$ & 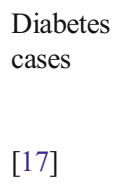 & $\begin{array}{l}\text { Diabetes } \\
\text { (type 2) } \\
\text { prevalence }\end{array}$ & $\begin{array}{l}\text { Diabetes- } \\
\text { related deaths } \\
\text { (cases) }\end{array}$ & $\begin{array}{l}\text { Mean diabetes- } \\
\text { related expenditure } \\
\text { per person with } \\
\text { diabetes (USD) }\end{array}$ & $\begin{array}{l}\text { Type } 1 \text { diabetes } \\
\text { cases }(0-14 \text { years }) \\
{[21]}\end{array}$ \\
\hline Percentage of total & & & & $35 \%$ & & $46 \%$ & & $40 \%$ \\
\hline Minimum & & & & & $1.28(\%)$ & & 20.89 & \\
\hline Maximum & & & $\$ 226$ & & $25.94(\%)$ & & 545.15 & \\
\hline Median & & & $\$ 4403$ & & $5.32(\%)$ & & 116.36 & \\
\hline
\end{tabular}

GDP gross domestic product, LIC low income countries, LMIC lower middle income countries, USD United States dollar

\section{References}

Papers of particular interest, published recently, have been highlighted as:

- Of importance

•- Of major importance

1. Omran A. The epidemiologic transition. A theory of the epidemiology of population change. Milbank Memorial Fund Q. 1971;49: 509-38.

2. Narayan KM, Ali MK, Koplan JP. Global noncommunicable diseases — where worlds meet. N Engl J Med. 2010;363(13):1196-8. doi:10.1056/NEJMp1002024.

3. Ziraba AK, Fotso JC, Ochako R. Overweight and obesity in urban Africa: a problem of the rich or the poor? BMC Public Health. 2009;9:465. doi:10.1186/1471-2458-9-465.

4. Atun R, Jaffar S, Nishtar S, Knaul FM, Barreto ML, Nyirenda M, et al. Improving responsiveness of health systems to noncommunicable diseases. Lancet. 2013;381(9867):690-7. doi:10. 1016/S0140-6736(13)60063-X.

5. WHO. Innovative care for chronic conditions: building blocks for action. Geneva: World Health Organization; 2002.

6. Bell J. Foreword II. In: Nolte E, McKee M, editors. Caring for people with chronic conditions: a health system perspective. Maidenhead: Open University Press; 2008.

7. WHO. Sustaining the drive to overcome the global impact of neglected tropical diseases: second WHO report on neglected diseases. Geneva: World Health Organization; 2013.

8. Beran D, Yudkin JS. Looking beyond the issue of access to insulin: what is needed for proper diabetes care in resource poor settings. Diabetes Res Clin Pract. 2010. doi:10.1016/j.diabres.2010.03.029.

9. Anderson R, Bury M. Living with chronic illness. London: Unwin Hyman Ltd.; 1988.

10. The World Bank. Country and Lending Groups. The World Bank, Washington D.C. 2013. http://data.worldbank.org/about/countryand-lending-groups. Accessed 22 July 2014.

11. Sumner A. Where do the world's poor live? A new update. Brighton: Institute of Development Studies; 2012.

12. WHO. World health statistics 2014. Geneva: World Health Organization; 2014.

13. WHO. Global status report on noncommunicable diseases. Geneva: World Health Organization; 2010.

14. Beaglehole R, Epping-Jordan J, Patel V, Chopra M, Ebrahim S, Kidd M, et al. Improving the prevention and management of chronic disease in low-income and middle-income countries: a priority for primary health care. Lancet. 2008;372(9642):940-9. doi:10. 1016/S0140-6736(08)61404-X.

15. Yach D, Hawkes C, Gould C, Hofman K. The global burden of chronic diseases. JAMA. 2004;291(2):2616-22.

16.• Levitt NS, Steyn K, Dave J, Bradshaw D. Chronic noncommunicable diseases and HIV-AIDS on a collision course: relevance for health care delivery, particularly in low-resource settings - insights from South Africa. Am J Clin Nutr. 2011;94(6):1690S-6. doi:10.3945/ ajcn.111.019075. Discusses double burden of diseases and health systems responses to this new challenge in low resource settings.

17. IDF. IDF diabetes atlas 6th edition. Brussels: International Diabetes Federation; 2013.

18. Barcelo A. Informe de Progresso: Iniciativa Centroamericana de Diabetes. Ciudad de Panama: Pan American Health Organisation; 2006.

19. Beran D, Atlan-Corea C, Tapia B, Martinez AJ. Report on the rapid assessment protocol for insulin access in Nicaragua. Managua: International Insulin Foundation and Handicap International; 2007.

20.• Silva-Matos C, Gomes A, Azevedo A, Damasceno A, Prista A, Lunet N. Diabetes in Mozambique: prevalence, management and healthcare challenges. Diabetes Metab. 2011;37(3):237-44. doi:10.1016/j.diabet. 2010.10.006. Population based study in Mozambique showing burden, number of undiagnosed cases andthe overall challenge of managing diabetes in one of the world's poorest countries.

21. IDF. IDF diabetes atlas 4th edition. Brussels: International Diabetes Federation; 2009.

22. Beran D, Yudkin JS, de Courten M. Access to care for patients with insulin-requiring diabetes in developing countries: case studies of Mozambique and Zambia. Diabetes Care. 2005;28(9):2136-40.

23. Muyer MT, Buntinx F, Mapatano MA, De Clerck M, Truyers C, Muls E. Mortality of young patients with diabetes in Kinshasa. DR Congo Diabet Med. 2010;27(4):405-11. doi:10.1111/j.1464-5491. 2010.02961.x.

24. Gill GV, Mbanya JC, Ramaiya KL, Tesfaye S. A sub-Saharan African perspective of diabetes. Diabetologia. 2009;52(1):8-16. doi:10.1007/s00125-008-1167-9.

25. Westcott M, Martiniuk AL, Fowler RA, Adhikari NK, Dalipanda T. Critical care resources in the Solomon Islands: a cross-sectional survey. BMC Int Health Hum Rights. 2012;12:1. doi:10.1186/ 1472-698X-12-1.

26. Travis P, Bennett S, Haines A, Pang T, Bhutta Z, Hyder A, et al. Overcoming health-systems constraints to achieve the Millennium Development Goals. Lancet. 2004;364(9437):900-6.

27. Clark NM. Management of chronic disease by patients. Annu Rev Public Health. 2003;24:289-313. doi:10.1146/annurev.publhealth. 24.100901.141021.

28. Mills A. Health care systems in low- and middle-income countries. N Engl J Med. 2014;370(6):552-7. doi:10.1056/NEJMra1110897. 
Short article giving a very comprehensive overview of the challenges of health systems in Low and Middle-Income Countries face.

29. Dubois CA, Singh D, Jiwani I. The human resource challenge in chronic care. In: Nolte E, McKee M, editors. Caring for people woth chronic conditions: a health system perspective. Maidenhead: Open University Press; 2008.

30. Beran D. Health systems and the management of chronic diseases: lessons from type 1 diabetes. Diabetes Manag. 2012;2(4):1-13. Review looking at management of chronic disease in health systems taking Type 1 diabetes as a tracer condition.

31. UN General Assembly. Political declaration of the high-level meeting of the General Assembly on the Prevention and Control of Noncommunicable Diseases. New York: United Nations General Assembly; 2012.

32. WHO. Global action plan for the prevention and control of noncommunicable diseases 2013-2020 - revised draft (Version dated 11 February 2013). Geneva: World Health Organization; 2013.

33. WHO. The World Health Report 2000 - health systems: improving performance. Geneva: World Health Organization; 2000.

34. WHO. Strengthening health systems to improve health outcomes: WHO's framework for action. Geneva: World Health Organization; 2007.

35. Reich MR, Takemi K, Roberts MJ, Hsiao WC. Global action on health systems: a proposal for the Toyako G8 summit. Lancet. 2008;371(9615):865-9.

36. WHO. Monitoring the building blocks of health systems: a handbook of indicators and their measurement strategies. Geneva: Switzerland: World Health Organization; 2010.

37. Abebe SM, Berhane Y, Worku A. Barriers to diabetes medication adherence in North West Ethiopia. Springer Plus. 2014;3:195. doi: 10.1186/2193-1801-3-195. Cross-sectional study looking at barriers to diabetes medicines and adherence in Ethiopia.

38. Abdraimova A, Beran D. Report on the rapid assessment protocol for insulin access in Kyrgyzstan. London: International Insulin Foundation; 2009.

39. IIF. Diabetes Foundation report on insulin-requiring diabetes in sub-Saharan Africa. London: International Insulin Foundation; 2005.

40. Beran D, Binh TV, Khue NT, Uoc HK, Toan LQ, Phuong NB, et al. Report on the rapid assessment protocol for insulin access in Vietnam. London: International Insulin Foundation; 2009.

41. Khalangot M, Tronko M. Primary care diabetes in Ukraine. Prim Care Diabetes. 2007;1(4):203-5. doi:10.1016/j.pcd.2007.10.041.

42. Allain TJ, van Oosterhout JJ, Douglas GP, Joukes S, Gadabu OJ, Darts C, et al. Applying lessons learnt from the 'DOTS' Tuberculosis Model to monitoring and evaluating persons with diabetes mellitus in Blantyre. Malawi Trop Med Int Health. 2011;16(9):1077-84. doi:10.1111/j.1365-3156.2011.02808.x.

43. Balabanova D, McKee M, Koroleva N, Chikovani I, Goguadze K, Kobaladze T, et al. Navigating the health system: diabetes care in Georgia. Health Policy Plan. 2009;24(1):46-54. doi:10.1093/ heapol/czn041.

44. Peck R, Mghamba J, Vanobberghen F, Kavishe B, Rugarabamu V, Smeeth L, et al. Preparedness of Tanzanian health facilities for outpatient primary care of hypertension and diabetes: a crosssectional survey. Lancet Glob Health. 2014;2(5):e285-92. doi:10. 1016/S2214-109X(14)70033-6.

45. Baruah MP, Pathak A, Kalra S, Das AK, Zargar AH, Bajaj S, et al. A revisit to prevailing care and challenges of managing diabetes in India: focus on regional disparities. Indian J Endocrinol Metab. 2014;18(3):254-63. doi:10.4103/2230-8210.131113.

46. Sabri AA, Qayyum MA, Saigol NU, Zafar K, Aslam F. Comparing knowledge of diabetes mellitus among rural and urban diabetics. Mcgill J Med. 2007;10(2):87-9.

47. Chary A, Greiner M, Bowers C, Rohloff P. Determining adult type 2 diabetes-related health care needs in an indigenous population from rural Guatemala: a mixed-methods preliminary study. BMC Health Serv Res. 2012;12:476. doi:10.1186/1472-6963-12-476.

48. Demaio AR, Otgontuya D, de Courten M, Bygbjerg IC, Enkhtuya $\mathrm{P}$, Oyunbileg J, et al. Exploring knowledge, attitudes and practices related to diabetes in Mongolia: a national population-based survey. BMC Public Health. 2013;13:236. doi:10.1186/1471-2458-13-236.

49. Beran D, Yudkin JS. Looking beyond the issue of access to insulin: what is needed for proper diabetes care in resource poor settings. Diabetes Res Clin Pract. 2010;88(3):217-21. doi:10.1016/j.diabres. 2010.03.029.

50. Beran D, Silva Matos C, The YJS, Diabetes UK. Mozambique Twinning Programme. Results of improvements in diabetes care in Mozambique: a reassessment 6 years later using the Rapid Assessment Protocol for Insulin Access. Diabet Med. 2010;27(8): 855-61. doi:10.1111/j.1464-5491.2010.03053.x.

51. IDF Africa Region. Type 2 diabetes clinical practice guidelines for sub-Saharan Africa. Dar es Salaam: International Diabetes Federation Africa Region; 2006.

52. Beran D, Abdraimova A, Akkazieva B, McKee M, Balabanova D, Yudkin JS. Diabetes in Kyrgyzstan: changes between 2002 and 2009. Int J Health Plann Manag. 2013;28(2):e121-37. doi:10. 1002/hpm.2145.

53. Widyahening IS, van der Graaf Y, Soewondo P, Glasziou P, van der Heijden GJ. Awareness, agreement, adoption and adherence to type 2 diabetes mellitus guidelines: a survey of Indonesian primary care physicians. BMC Fam Pract. 2014;15:72. doi:10.1186/1471-229615-72.

54. Beran D, Higuchi M. Delivering diabetes care in the Philippines and Vietnam: policy and practice issues. Asia Pac J Public Health. 2013;25(1):92-101. doi:10.1177/1010539511412177.

55. Fisher EB, Boothroyd RI, Coufal MM, Baumann LC, Mbanya JC, Rotheram-Borus MJ, et al. Peer support for self-management of diabetes improved outcomes in international settings. Health Aff (Millwood). 2012;31(1):130-9. doi:10.1377/hlthaff.2011.0914.

56. Ocvirk S, Kistler M, Khan S, Talukder SH, Hauner H. Traditional medicinal plants used for the treatment of diabetes in rural and urban areas of Dhaka, Bangladesh - an ethnobotanical survey. J Ethnobiol Ethnomedicine. 2013;9:43. doi:10.1186/1746-4269-943.

57. Katemo M, Mpiana PT, Mbala BM, Mihigo SO, Ngbolua KN, Tshibangu DS, et al. Ethnopharmacological survey of plants used against diabetes in Kisangani City (DR Congo). J Ethnopharmacol. 2012;144(1):39-43. doi:10.1016/j.jep.2012.08.022.

58. Diallo A, Traore MS, Keita SM, Balde MA, Keita A, Camara M, et al. Management of diabetes in Guinean traditional medicine: an ethnobotanical investigation in the coastal lowlands. J Ethnopharmacol. 2012;144(2):353-61. doi:10.1016/j.jep.2012.09. 020 .

59. Khalil SH, Zaki A, Ibrahim AM, El-Moughazi AM, Khater AM, Youssef AM, et al. Pattern of use of complementary and alternative medicine among type 2 diabetes mellitus patients in Alexandria, Egypt. J Egypt Publ Health Assoc. 2013;88(3):137-42. doi:10. 1097/01.EPX.0000440994.89503.45.

60. Mbeh GN, Edwards R, Ngufor G, Assah F, Fezeu L, Mbanya JC. Traditional healers and diabetes: results from a pilot project to train traditional healers to provide health education and appropriate health care practices for diabetes patients in Cameroon. Glob Health Promot. 2010;17(2 Suppl):17-26. doi:10.1177/ 1757975910363925.

61. Katulanda P, Constantine GR, Weerakkody MI, Perera YS, Jayawardena MG, Wijegoonawardena $\mathrm{P}$, et al. Can we bridge the gap? Knowledge and practices related to diabetes mellitus among general practitioners in a developing country: a cross sectional study. Asia Pac Fam Med. 2011;10(1):15. doi:10.1186/1447-056X-10-15.

62. Mendis S, Al Bashir I, Dissanayake L, Varghese C, Fadhil I, Marhe E, et al. Gaps in capacity in primary care in low-resource settings for 
implementation of essential noncommunicable disease interventions. Int J Hypertens. 2012;2012:584041. doi:10.1155/2012/ 584041.

63. Shankhdhar K, Shankhdhar LK, Shankhdhar U, Shankhdhar S. Diabetic foot problems in India: an overview and potential simple approaches in a developing country. Curr Diab Rep. 2008;8(6): 452-7.

64. Kengne AP, Fezeu L, Sobngwi E, Awah PK, Aspray TJ, Unwin $\mathrm{NC}$, et al. Type 2 diabetes management in nurse-led primary healthcare settings in urban and rural Cameroon. Prim Care Diabetes. 2009;3(3):181-8. doi:10.1016/j.pcd.2009.08.005.

65. Labhardt ND, Balo JR, Ndam M, Grimm JJ, Manga E. Task shifting to non-physician clinicians for integrated management of hypertension and diabetes in rural Cameroon: a programme assessment at two years. BMC Health Serv Res. 2010;10:339. doi:10. 1186/1472-6963-10-339.

66. Amoah AG, Owusu SK, Acheampong JW, Agyenim-Boateng K, Asare HR, Owusu AA, et al. A national diabetes care and education programme: the Ghana model. Diabetes Res Clin Pract. 2000;49(23):149-57.

67. Zamzam S, Anoosheh M, Ahmadi F. Barriers to diabetes control from Syrian women's perspectives. Jpn J Nurs Sci: JJNS. 2013;10(1):121-9. doi:10.1111/j.1742-7924.2012.00218.x.

68. WHO. Prioritized research agenda for prevention and control of noncommunicable diseases. Geneva: World Health Organization; 2011.

69. WHO. WHO model list of essential medicines 18th list. Geneva: World Health Organization; 2013.

70. Cameron A, Ewen M, Ross-Degnan D, Ball D, Laing R. Medicine prices, availability, and affordability in 36 developing and middleincome countries: a secondary analysis. Lancet. 2009;373(9659): 240-9. doi:10.1016/S0140-6736(08)61762-6.

71. Mendis S, Fukino K, Cameron A, Laing R, Filipe Jr A, Khatib O, et al. The availability and affordability of selected essential medicines for chronic diseases in six low- and middle-income countries. Bull World Health Organ. 2007;85(4):279-88.

72. Gill GV, Yudkin JS, Keen H, Beran D. The insulin dilemma in resource-limited countries. A way forward? Diabetologia. 2010. doi:10.1007/s00125-010-1897-3.

73. Gill G, Price C, English P, Eriksson-Lee J. Traditional clay pots as storage containers for insulin in hot climates. Trop Doct. 2002;32(4):237-8.

74. Life for a Child. Life for a Child. 2013. http://www.lifeforachild.idf. org/. Accessed 11 March 2014.

75. Insulin for Life. Insulin for Life. 2011. http://www.insulinforlife. org/navigate-to/about-us.html. Accessed 11 March 2014.

76. Novo Nordisk. Changing Diabetes in Children. 2010. http://www. changingdiabetesaccess.com/programmes_and_partnerships/ diabetes in children.asp. Accessed 11 March 2014.

77. Novo Nordisk. Novo Nordisk Annual Report 2013: Novo Nordisk; 2013.

78. Beran D, Basey M, Wirtz V, Kaplan W, Atkinson M, Yudkin JS. On the road to the insulin centenary. Lancet. 2012;380(9854):1648.

79. Beran D, Perrin C, Billo N, Yudkin JS. Improving global access to medicines for non-communicable diseases. Lancet Glob Health. 2014;2(10):e561-2. doi:10.1016/S2214-109X(14)70189-5.

80. Silva-Matos C, Beran D. Non-communicable diseases in Mozambique: risk factors, burden, response and outcomes to date. Glob Health. 2012;8(1):37. doi:10.1186/1744-8603-8-37.

81. Nugent R, Feigl A. Where have all the donors gone? Scarce donor funding for non-communicable diseases. Washington D.C: Center for Global Development; 2011.

82. Stuckler D, King L, Robinson H, McKee M. WHO's budgetary allocations and burden of disease: a comparative analysis. Lancet. 2008;372(9649):1563-9. doi:10.1016/S0140-6736(08)61656-6.
83. Fuster V, Voute J. MDGs: chronic diseases are not on the agenda. Lancet. 2005;366(9496):1512-4.

84. WHO. The World Health Report 2010: health system financing: the path to universal coverage. Geneva: World Health Organization; 2010.

85. WHO. Follow-up to the political declaration of the high-level meeting of the General Assembly on the Prevention and Control of Noncommunicable Diseases. Geneva: World Health Organization; 2013. Contract No.: WHA66.10; Agenda item 13.1; Agenda item 13.2 .

86. Beran D, Silva-Matos C. Report on the rapid assessment protocol for insulin access in Mozambique. London: International Insulin Foundation; 2009

87. de-Graft Aikins A, Kushitor M, Koram K, Gyamfi S, Ogedegbe G. Chronic non-communicable diseases and the challenge of universal health coverage: insights from community-based cardiovascular disease research in urban poor communities in Accra, Ghana. BMC Public Health. 2014;14 Suppl 2:S3.

88. Beran D. Difficulties facing the provision of care for multimorbidity in low-income countries. In: Sartorius N, Holt RIG, Maj M, editors. Comorbidity of mental and physical disorders. Basel: Key Issues Ment Health; 2015.

89. Harries AD, Jahn A, Zachariah R, Enarson D. Adapting the DOTS framework for tuberculosis control to the management of noncommunicable diseases in sub-Saharan Africa. PLoS Med. 2008;5(6):e124. doi:10.1371/journal.pmed.0050124.

90. Rabkin M, Melaku Z, Bruce K, Reja A, Koler A, Tadesse Y, et al. Strengthening health systems for chronic care: leveraging HIV programs to support diabetes services in Ethiopia and Swaziland. J Trop Med. 2012;2012:137460. doi:10.1155/ 2012/137460.

91. Tragard A, Shrestha IB. System-wide effects of Global Fund investments in Nepal. Health Policy Plan. 2010;25 Suppl 1:i58-62. doi: 10.1093/heapol/czq061.

92. Schouten EJ, Jahn A, Ben-Smith A, Makombe SD, Harries AD, Aboagye-Nyame F, et al. Antiretroviral drug supply challenges in the era of scaling up ART in Malawi. J Int AIDS Soc. 2011;14 Suppl 1:S4. doi:10.1186/1758-2652-14-S1-S4.

93.• Hogerzeil HV, Liberman J, Wirtz VJ, Kishore SP, Selvaraj S, Kiddell-Monroe R, et al. Promotion of access to essential medicines for non-communicable diseases: practical implications of the UN political declaration. Lancet. 2013. doi:10.1016/S0140-6736(12) 62128-X. Article describing the challenges and possible solutions to the issue of access to medicines for NCDs.

94. WHO. A comprehensive global monitoring framework, including indicators, and a set of voluntary global targets for the prevention and control of noncommunicabale diseases - revised WHO discussion paper (version dated 25 July 2012). Geneva: World Health Organization; 2012.

95. Wagner EH, Austin BT, Davis C, Hindmarsh M, Schaefer J, Bonomi A. Improving chronic illness care: translating evidence into action. Health Aff (Millwood). 2001;20(6):64-78.

96. Scambler G, Hopkins A. Accomodating epilepsy in families. In: Anderson R, Bury M, editors. Living with chronic illness. London: Unwin Hyman Ltd.; 1988.

97. Beran D. Developing a hierarchy of needs for Type 1 diabetes. Diabet Med. 2014;31(1):61-7. doi:10.1111/dme.12284. Qualitative study looking at the needs of people with Type 1 diabetes highlighting the health system and non-health system needs that people require.

98. WHO. Country Health Profiles. 2014. http://www.who.int/ countries/. Accessed 26 October 2014.

99. World Bank. GDP per capita (current US\$). World Bank 2014. http://data.worldbank.org/indicator/NY.GDP.PCAP.CD. Accessed 27 October 2014. 